\title{
Long-term outcomes of initially conservatively treated midshaft clavicle fractures
}

\author{
Gwan Bum Lee, Hyojune Kim, In-Ho Jeon, Kyoung Hwan Koh \\ Department of Orthopedic Surgery, Asan Medical Center, University of Ulsan College of Medicine, Seoul, Korea
}

\begin{abstract}
Background: Recent studies about completely displaced midshaft clavicle fractures have reported that their nonunion/malunion rates were significantly higher in conservatively treated patients compared to surgically treated patients. The purpose of this study was to evaluate the factors associated with treatment decisions for midshaft clavicle fractures and also the factors that affect patient satisfaction with their treatment choice.

Methods: We retrospectively reviewed the records of 75 patients who had been diagnosed with a midshaft clavicle fracture and were treated conservatively at a single institution between March 1, 2013, and December 31, 2014. Their medical records were reviewed to investigate the severity of the initial vertical displacement. A telephone survey was carried out to identify the presence of any patient-perceived deformity and determine if the patient eventually underwent surgery and whether the patient would prefer surgery if the injury recurred.

Results: Significantly more patients with vertical displacement $\geq 100 \%(9 / 28)$ eventually underwent surgery compared to patients with vertical displacement $<100 \%(3 / 32, p=0.028)$. Patients with vertical displacement $\geq 100 \%(13 / 28)$ were significantly more likely to prefer surgery compared to patients with vertical displacement $<100 \%(7 / 32, \mathrm{p}=0.044)$. Among the conservatively treated patients, nine of 32 participants with a patient-perceived deformity and one of 16 without a patient-perceived deformity responded that they would prefer to receive surgery in same situation in the future $(\mathrm{p}=0.079)$.

Conclusions: Patients with a midshaft clavicle fracture with vertical displacement of $\geq 100 \%$ may eventually require surgical treatment. When conservative treatment is carried out, the long-term patient results may be unsatisfactory due to perceived residual deformities.
\end{abstract}

Keywords: Mid-shaft clavicle fracture; Conservative treatment; Shared decision-making; Deformity; Vertical displacement

\section{INTRODUCTION}

Clavicle fracture is a common injury, with midshaft fractures accounting for about $80 \%$ of all clavicle fractures [1,2]. In the $1960 \mathrm{~s}$, Neer [3] and Rowe [4] reported a nonunion rate of $0.1-0.7 \%$ in conservatively treated midshaft clavicle fractures.
Since then, most midshaft clavicle fractures have been treated effectively with conservative approaches using an arm sling or figure-of-eight bandage [5]. Recent studies have not reported significant differences in the functional outcomes between conservative and surgical treatments for displaced midshaft clavicle fractures. However, the nonunion/malunion rates have been sig-

Received: December 18, 2020 Revised: January 17, 2021

Accepted: January 20, 2021

Correspondence to: Kyoung Hwan Koh

Department of Orthopedic Surgery, Asan Medical Center, University of Ulsan College of Medicine, 88 Olympic-ro 43-gil, Songpa-gu, Seoul 05505, Korea

Tel: +82-2-3010-3530, Fax: +82-2-488-7877, E-mail: osdoc.koh@gmail.com, ORCID: https://orcid.org/0000-0002-6181-9621

Financial support: None.

Conflict of interest: None.

Copyright@ 2021 Korean Shoulder and Elbow Society. All Rights Reserved.

This is an Open Access article distributed under the terms of the Creative Commons Attribution Non-Commercial License (http://creativecommons.org/licenses/by-nc/4.0/) which permits unrestricted non-commercial use, distribution, and reproduction in any medium, provided the original work is properly cited. 
nificantly higher in patients treated conservatively [6-8], especially those with completely displaced midshaft clavicle fractures with a displacement of $\geq 100 \%$, where a $15 \%-20 \%$ nonunion rate has been reported $[9,10]$.

These recent long-term outcomes of increased nonunion/malunion rates after conservative treatment have changed the indications for surgery when treating midshaft clavicle fractures. However, if the long-term functional outcome is not significantly different between conservative and surgical treatments and both treatment methods provide good outcomes, other factors may also be needed to aid in decision-making. Because both treatment methods have their own pros and cons, clinicians must consider not only the long-term outcome of the treatment methods, but also the patient's condition and the discomfort experienced at the time of injury or the expected satisfaction with the final outcome of the treatment. Further, shared decision-making after sufficient consultation between patient and surgeon can lead to better outcomes when selecting treatment plans for orthopedic conditions [11].

We wondered if any factors present at the time of injury were associated with the patient's decision to proceed with surgical treatment. We also investigated if there were common characteristics among patients who were satisfied with their treatment method. The objective of this study was to investigate the hypothesis that patients with midshaft clavicle fracture with a displacement of $\geq 100 \%$ will eventually undergo surgical treatment and will be satisfied with the surgical treatment.

\section{METHODS}

All procedures performed in studies involving human participants were carried out in accordance with the ethical standards of the Institutional Review Board of Asan Medical Center (IRB No. 2018-1091), and with the 1964 Declaration of Helsinki and its later amendments or comparable ethical standards. Informed consent was obtained from all individual participants included in the study.

\section{Patients and Study Design}

We retrospectively reviewed the medical records of patients who were diagnosed with a midshaft clavicle fracture in the outpatient clinic and emergency department of Asan Medical Center in Seoul, South Korea, between March 1, 2013 and December 31, 2014.

During the eligibility period, we identified 81 patients from 19 to 70 years of age who were diagnosed with a midshaft clavicle fracture. We excluded five patients who had been previously treated for fracture of the ipsilateral clavicle and one patient who underwent surgical treatment at the time of injury due to other concomitant fractures. The patients were treated conservatively with either an arm sling or a figure-of-eight bandage regardless of any comminution and segmentation of the fracture. These patients were informed that surgical treatments should be considered if the displacement of the fracture increases, if pain persists for more than 6 months from the time of fracture, or if nonunion occurs during the follow-up period. An arm sling or figure-ofeight bandage was used for 6 weeks; tolerable range of motion was allowed, while excessive motion was restricted. Patients were referred to their local primary hospital for regular follow-up. These patients were instructed to re-visit our clinic if a change in treatment plan was needed.

In May 2018, we reviewed the medical records of the 75 eligible patients to investigate their age at the time of injury, sex, dominant arm, side of injury (right or left), injury mechanism, and any other concomitant injuries and medical comorbidities. We reviewed the initial radiographs of all patients and then conducted a telephone survey to evaluate the clinical results at the time of the study.

\section{Radiological Evaluation}

Clavicle fractures were classified according the arbeitsgemeinschaft für osteosynthesefragen (AO) fracture and Dislocation Classification Compendium, which was revised in 2018 [12]. Shortening of the clavicle was defined as the difference between the intact clavicle length and the injured clavicle length as measured on an anteroposterior X-ray. Vertical displacement was assessed by dividing the distance between the superior cortex of
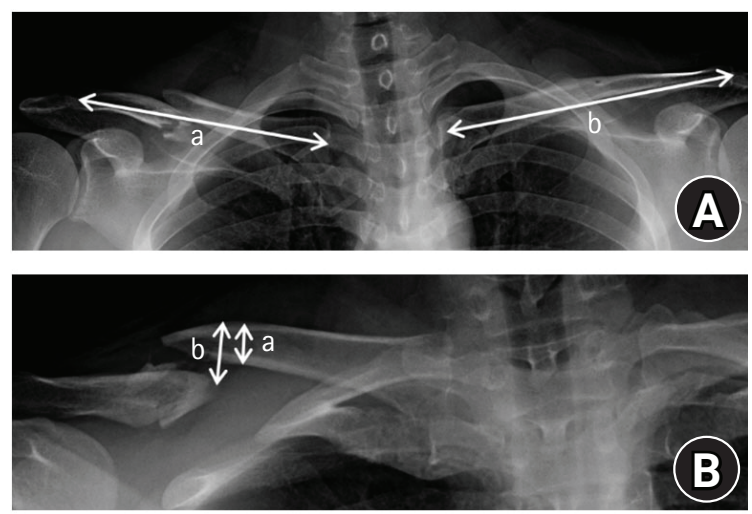

Fig. 1. The radiologic assessment of the initial X-ray of a patient with a midshaft clavicle fracture. (A) The calculation method for shortening the clavicle length from both clavicle anteroposterior view $\mathrm{X}$-rays: the length of the contralateral clavicle (b)-the length of the fractured clavicle (a) ( $\mathrm{mm}$ ). (B) The calculation method for vertical displacement of the clavicle on a $30^{\circ}$ cephalic tilt view X-ray: cortical displacement (b)/one bone width of the clavicle (a) $\times 100(\%)$. 
both fractured fragments by one bone width of the injured clavicle on a $30^{\circ}$ cephalic tilt view X-ray (Fig. 1) $[13,14]$. Patients were classified according to the presence or absence of cortical contact.

\section{Clinical Survey}

In May 2018, 60 of the 75 eligible patients participated in a telephone survey. Patients with pain or other discomfort were encouraged to visit our clinic for further evaluation and counseling. In the telephone survey, the patients were asked whether they eventually received surgery at our hospital or another clinic. For those who underwent surgery, questions about why and when it had taken place were also asked. Patients were also queried about any complications after the surgery and the presence of discomfort or a patient-perceived subjective deformity.

We also verified whether the patient had a confirmation of union from the treating hospital. As part of the clinical assessment, the American Shoulder and Elbow Surgeons (ASES) and pain numeric rating scale (NRS) scores at the time of the telephone survey were also assessed [15]. If the patients complained about pain near the glenohumeral joint area, the degree of pain around the clavicular area was reassessed to differentiate it from other pain due to glenohumeral joint disease. The telephone surveys were performed by a physician who was not involved in treating the patients. Finally, the patients were asked if they would or would not elect to receive surgery again if they were in same situation of clavicle fracture, and the main reason for their answer was recorded.

\section{Statistical Analysis}

To analyze the factors associated with the decision to choose surgical treatment, variables including age, sex, involvement of the dominant arm, AO classification, vertical displacement distance, and amount of shortening were included in the univariate analysis (chi-square test for categorical variables and t-test for continuous variables). Variables with a $\mathrm{p}$-value $<0.2$ upon univariate analysis were included in the multivariable logistic regression analysis. A p-value $<0.05$ was considered statistically significant.

\section{RESULTS}

An analysis of the differences in clinical and radiological parameters between patients who initially received operative treatment and those who received conservative treatment is shown in Table 1. There were no significant differences between the two groups in age, sex, involvement of the dominant arm, in-
Table 1. Clinical and radiological data of patients with midshaft clavicle fracture

\begin{tabular}{|c|c|c|c|}
\hline Variable & $\begin{array}{l}\text { Operative } \\
\text { treatment }\end{array}$ & $\begin{array}{c}\text { Conservative } \\
\text { treatment }\end{array}$ & $\mathrm{p}$-value \\
\hline Number & 12 & 48 & \\
\hline Sex (male:female) & $9: 3$ & $40: 8$ & 0.505 \\
\hline Age (yr) & 44.2 & 46.3 & 0.668 \\
\hline $\begin{array}{l}\text { Dominant arm involvement, } \\
\mathrm{n}(\%)\end{array}$ & $5(41.7)$ & $22(45.8)$ & 0.795 \\
\hline Injury mechanism & & & 0.781 \\
\hline Motorcycle TA & 1 & 4 & \\
\hline In car TA & 2 & 5 & \\
\hline Pedestrian TA & 0 & 2 & \\
\hline Slip down & 8 & 34 & \\
\hline Fall from a height & 0 & 2 & \\
\hline Others & 1 & 1 & \\
\hline AO classification & & & 0.719 \\
\hline Simple & 6 & 20 & \\
\hline Wedge & 3 & 18 & \\
\hline Multi-fragmentary & 3 & 10 & \\
\hline Shortening $(\mathrm{mm})$ & -7.8 & -3.7 & 0.185 \\
\hline Displacement (\%) & 126.3 & 90.9 & 0.095 \\
\hline Displacement & & & $0.028^{*}$ \\
\hline$<100 \%$ & 3 & 29 & \\
\hline$\geq 100 \%$ & 9 & 19 & \\
\hline \multicolumn{4}{|l|}{ Reason for operation } \\
\hline Doctor's opinion & 6 & & \\
\hline Pain & 4 & & \\
\hline Nonunion & 1 & & \\
\hline Others & 1 & & \\
\hline \multicolumn{4}{|l|}{ Time to operation } \\
\hline$<1 \mathrm{wk}$ & 11 & & \\
\hline$>6 \mathrm{mo}$ & 1 & & \\
\hline \multicolumn{4}{|l|}{ Postoperative complication } \\
\hline Implant irritation & 1 & & \\
\hline Nonunion & 1 & & \\
\hline Wound problem & 1 & & \\
\hline
\end{tabular}

TA: traffic accident, AO: arbeitsgemeinschaft für osteosynthesefragen. ${ }^{*} \mathrm{p}<0.05$.

jury mechanism, or AO classification (Table 1).

There was no significant difference in the average clavicle shortening distance in patients who received operative treatment $(7.8 \mathrm{~mm})$ and in patients who received conservative treatment (3.7 mm, p = 0.185). There was also no significant difference in the mean vertical displacement between patients who underwent operative treatment $(126.3 \%)$ and patients who received conservative treatment $(90.9 \%, \mathrm{p}=0.095)$. Significantly more patients $(9 / 28,32.1 \%)$ with vertical displacement $>100 \%$ underwent operative treatment than patients $(3 / 32,9.4 \%)$ with vertical displacement $<100 \%(\mathrm{p}=0.028)$ (Table 1$)$. 
In the telephone survey, significantly more patients (32/48, $66.7 \%$ ) reported a subjective deformity after receiving conservative treatment than patients $(2 / 12,16.7 \%)$ who initially underwent operative treatment $(\mathrm{p}=0.002)$. There was no significant difference in the number of patients with a confirmed union $(\mathrm{P}>0.999)$, ASES score $(\mathrm{p}=0.784)$, or a pain NRS score $(\mathrm{p}=0.795)$ between participants who underwent operative treatment and those who received conservative treatment (Table 2).

When responding to the question about whether the patient would choose to undergo surgery in the same situation of clavicle fracture in the future, 10 of 48 (20.8\%) respondents who initially received conservative treatment answered that they would choose surgery instead. The main reasons for that answer were delayed union or nonunion in four patients, a patient-perceived deformity in five patients, and remaining pain in one patient. More patients $(10 / 12,83.3 \%)$ who had undergone surgery responded that they would choose surgery again if presented with the same situation than patients who received conservative management $(10 / 48,20.8 \%$; $\mathrm{p}<0.001)$. Significantly more patients $(13 / 28,46.4 \%)$ with vertical displacement $>100 \%$ responded that they would elect for surgery again if in the same situation than patients $(7 / 32,21.9 \%)$ with vertical displacement $<100 \%$ $(\mathrm{p}=0.044)$ (Table 3).

In the analysis of patients who received conservative treatment, five of $19(26.3 \%)$ participants with vertical displacement $>100 \%$ and five of 29 (17.2\%) patients with vertical displacement $<100 \%$ responded that they would elect for surgery in the same situation again; this result had no significance difference $(p=0.449)$. Significantly fewer patients $(7 / 44,15.9 \%)$ with confirmed union responded that they would elect to have surgery again in the same situation than patients $(3 / 4,75 \%)$ with nonunion $(\mathrm{p}=0.005)$. Nine of $32(28.1 \%)$ patients with a patient-perceived deformity and one of 16 (6.25\%) without a patient-perceived deformity responded that they would choose surgery if in the same situation, which showed no significant difference $(p=0.079)$.

Variables with p-values $<0.2$ upon univariate analysis of patient willingness to opt for surgery in the same situation included the following: "previous treatment method" $(\mathrm{p}<0.001)$, "vertical displacement" ( $p=0.044)$, and "confirmation of union" $(p=0.186)$ (Table 3). A multiple logistic regression analysis was performed using these three variables. "Treatment method" $(p=0.001)$ significantly influenced the decision to undergo an operation in the same future situation, but "vertical displacement" $(p=0.246)$ and "confirmation of union" ( $\mathrm{p}=0.114)$ were not significantly associated.
Table 2. Telephone survey results

\begin{tabular}{lccc}
\hline Variable & $\begin{array}{c}\text { Operative } \\
\text { treatment }\end{array}$ & $\begin{array}{c}\text { Conservative } \\
\text { treatment }\end{array}$ & p-value \\
\hline Union & 11 & 44 & 1.000 \\
$\quad$ Yes & 1 & 4 & \\
$\quad$ No & & & $0.002^{*}$ \\
Patient-perceived deformity & 2 & 32 & \\
$\quad$ Yes & 10 & 16 & \\
$\quad$ No & 92.4 & 93.6 & 0.784 \\
ASES score & 0.5 & 0.4 & 0.795 \\
Pain (NRS) score &
\end{tabular}

ASES: American Shoulder and Elbow Surgeons, NRS: numeric rating scale.

${ }^{*} \mathrm{p}<0.05$.

Table 3. Patient willingness to elect surgery in the same situation

\begin{tabular}{lccc}
\hline Variable & Yes & No & p-value \\
\hline $\begin{array}{l}\text { Treatment method } \\
\quad \text { Operative }\end{array}$ & 10 & 2 & $<0.001^{*}$ \\
$\quad$ Conservative & 10 & 38 & \\
Displacement & & & $0.044^{*}$ \\
$\quad<100 \%$ & 7 & 25 & \\
$\quad 100 \%$ & 13 & 15 & \\
Union & & & 0.186 \\
$\quad$ Yes & 17 & 38 & \\
$\quad$ No & 3 & 2 & \\
Patient-perceived deformity & & & 0.854 \\
$\quad$ Yes & 11 & 23 & \\
$\quad$ No & 9 & 17 & \\
\hline
\end{tabular}

${ }^{*} \mathrm{p}<0.05$.

\section{DISCUSSION}

Patients with midshaft clavicle fracture and a vertical displacement of $\geq 100 \%$ were more likely to eventually undergo surgical treatment than patients with a vertical displacement $<100 \%$. Of the 12 patients who had undergone conservative treatment first but eventually received surgery, four chose surgery due to severe pain caused by the fracture. When the vertical displacement is large, any fragments can irritate the skin and periosteum, resulting in greater pain and discomfort [16]. However, due to our small sample size and retrospective study design, we could not analyze the statistical difference in the degree of subjective pain at the initial trauma between the conservative treatment group patients and the operative treatment group patients. Further studies with larger sample sizes that consider this subjective pain as a factor in decision-making will be required.

A substantial number of patients who underwent conservative 
treatment responded that they would elect for surgery instead if presented with the same situation. This finding likely resulted not only from the presence of nonunions but also patient-perceived deformities or persisting pain until union is achieved, which can result when conservative treatment is chosen as the initial treatment method.

In our study, patients who had undergone surgery had a tendency to respond that they would elect for surgery if faced with the same situation in the future, while patients who had undergone conservative treatment the first time around had a tendency to respond that they would select conservative treatment again. In other words, patients tend to regard the previous treatment method as the correct decision and are likely to select the same method if they experience a similar future injury. However, patients with vertical displacement of $\geq 100 \%$ were significantly more likely to report that they would prefer surgery if they were to experience a similar injury compared to patients who experienced a vertical displacement of $<100 \%$.

In the analysis of patients who received conservative treatment, patients with nonunion were significantly more likely to prefer surgery if in the same situation in the future, while patients with a perceived deformity had a tendency (that was not statistically significant) to respond that they would elect for surgery if they ever faced the same situation. This result is in line with previous reports about the consequences of conservative treatment in vertically displaced midshaft clavicle fractures $[5,17]$. Based on these results, patient-perceived deformity and nonunion of the fracture are likely the most important factors to patients following treatment and affect the satisfaction of patients regarding their fracture treatment method.

Patients with midshaft clavicle fracture with an initial vertical displacement of $\geq 100 \%$ are more likely to eventually undergo surgical treatment due to acute pain, severe deformity, or another doctor's second opinion. Although there may be no functional deficits, deformity and nonunion may occur in those who choose conservative treatment; therefore, these patients may not be satisfied with their fracture treatment method after some time has passed. This information can be helpful for surgeons and patients when making shared decisions about treatment.

This study had an inherent weakness due to its retrospective study design and small sample size. In addition, the telephone survey did not allow us to confirm the union status of the fracture site with a radiographic examination, and we also could not assess the exact residual deformity of the clavicle (including shortening and angulation) radiographically. Finally, because only the subjective patient-reported outcomes were evaluated by telephone survey, we were unable to conduct an objective evalua- tion in person and therefore could not objectively assess the longterm outcomes. However, we were able to obtain responses from about $80 \%$ of patients, and non-responders did not differ in their demographic characteristics (such as age or sex) from the responders. Because the objective of our study was to determine the factors that influence the treatment strategy selection at the time of trauma, the initial radiographic analysis was sufficient to proceed with our study.

Patients who receive conservative treatment for midshaft clavicle fracture with a vertical displacement of $\geq 100 \%$ may eventually require surgical treatment. If conservative treatment is continued, the patients may be relatively dissatisfied with any residual subjective deformity even though there may be no functional deficit or decrease in union rate compared to patients who initially received surgery.

\section{ORCID}

Gwan Bum Lee https://orcid.org/0000-0003-4471-0103 Hyojune Kim https://orcid.org/0000-0001-7665-536X In-Ho Jeon https://orcid.org/0000-0002-9289-9193 Kyoung Hwan Koh https://orcid.org/0000-0002-6181-9621

\section{REFERENCES}

1. Nordqvist A, Petersson C. The incidence of fractures of the clavicle. Clin Orthop Relat Res 1994;(300):127-32.

2. Postacchini F, Gumina S, De Santis P, Albo F. Epidemiology of clavicle fractures. J Shoulder Elbow Surg 2002;11:452-6.

3. NEER CS 2nd. Nonunion of the clavicle. J Am Med Assoc 1960;172:1006-11.

4. Rowe CR. An atlas of anatomy and treatment of midclavicular fractures. Clin Orthop Relat Res 1968;58:29-42.

5. Fuglesang HF, Flugsrud GB, Randsborg PH, Stavem K, Utvag SE. Radiological and functional outcomes 2.7 years following conservatively treated completely displaced midshaft clavicle fractures. Arch Orthop Trauma Surg 2016;136:17-25.

6. Lenza M, Buchbinder R, Johnston RV, Belloti JC, Faloppa F. Surgical versus conservative interventions for treating fractures of the middle third of the clavicle. Cochrane Database Syst Rev 2013;(6):CD009363.

7. McKee RC, Whelan DB, Schemitsch EH, McKee MD. Operative versus nonoperative care of displaced midshaft clavicular fractures: a meta-analysis of randomized clinical trials. J Bone Joint Surg Am 2012;94:675-84.

8. Woltz S, Stegeman SA, Krijnen P, et al. Plate fixation compared with nonoperative treatment for displaced midshaft clavicular 
fractures: a multicenter randomized controlled trial. J Bone Joint Surg Am 2017;99:106-12.

9. Eskola A, Vainionpaa S, Myllynen P, Patiala H, Rokkanen P. Outcome of clavicular fracture in 89 patients. Arch Orthop Trauma Surg 1986;105:337-8.

10. Robinson CM, Court-Brown CM, McQueen MM, Wakefield AE. Estimating the risk of nonunion following nonoperative treatment of a clavicular fracture. J Bone Joint Surg Am 2004; 86:1359-65.

11. Slover J, Shue J, Koenig K. Shared decision-making in orthopaedic surgery. Clin Orthop Relat Res 2012;470:1046-53.

12. Kellam JF, Meinberg EG, Agel J, et al. Fracture and Dislocation Classification Compendium-2018: International Comprehensive Classification of Fractures and Dislocations Committee. J Orthop Trauma 2018;32 Suppl 1:S1-170.
13. Omid R, Kidd C, Yi A, Villacis D, White E. Measurement of clavicle fracture shortening using computed tomography and chest radiography. Clin Orthop Surg 2016;8:367-72.

14. Plocher EK, Anavian J, Vang S, Cole PA. Progressive displacement of clavicular fractures in the early postinjury period. J Trauma 2011;70:1263-7.

15. Richards RR, An KN, Bigliani LU, et al. A standardized method for the assessment of shoulder function. J Shoulder Elbow Surg 1994;3:347-52.

16. Nencini S, Ivanusic JJ. The physiology of bone pain. how much do we really know. Front Physiol 2016;7:157.

17. Cha SD, Chung ST, Kim YH, Park SJ. The analysis of conservative treatment in midshaft fractures of clavicle. J Korean Shoulder Elbow Soc 2010;13:27-33. 